\title{
Study of hundred cases of infertility in polycystic ovarian syndrome and its management outcome
}

\author{
Kruti J. Deliwala, Zalak J. Patel*, Parul T. Shah, Dhruvit Dholakiya
}

Department of Obstetrics and Gynecology, SVP Hospital and NHL Medical College, Ahmedabad, Gujarat, India

Received: 04 June 2020

Accepted: 06 July 2020

*Correspondence:

Dr. Zalak J. Patel,

E-mail: zalakpate10106@gmail.com

Copyright: (C) the author(s), publisher and licensee Medip Academy. This is an open-access article distributed under the terms of the Creative Commons Attribution Non-Commercial License, which permits unrestricted non-commercial use, distribution, and reproduction in any medium, provided the original work is properly cited.

\begin{abstract}
Background: Polycystic ovarian syndrome (PCOS) is relatively common endocrine disorder in reproductive aged women, which leads to reproductive, metabolic and endocrine abnormality. About 70 to $80 \%$ patients with PCOS have complained of infertility due to anovulation. Due to advanced diagnostic facility by endoscopic evaluation in infertility, incidence of PCOS has increased now a days.

Methods: This is study of 100 cases of infertility with polycystic ovarian syndrome and its pregnancy outcome. In this study, from May 2019 to April 2020, 100 cases of infertility with PCOS were studied at tertiary care hospital. Hormonal assay, ultrasound and laparoscopy were used as diagnostic technique. Clomiphene citrate, letrozole, metformin, and laparoscopic ovarian drilling were used as treatment modalities.

Results: The maximum number of patients in the study group are seen in the age group of 21-25 years. Menstrual irregularities are the most common presenting symptom affecting $70 \%$ females. Primary infertility is most commonly associated with PCOS. In PCOS, there is increased LH:FSH ratio. On USG examination, there are enlarged ovaries in $82 \%$ cases.

Conclusions: PCOS is an emerging disease of new generation with high prevalence in infertile women. After proper diagnosis, management with lifestyle modification, pharmacotherapy with clomiphene citrate, letrozole and metformin are used as per necessities. Operative laparoscopy with ovarian drilling is the main treatment which results in good conception rate.
\end{abstract}

Keywords: Clomiphene citrate, Infertility, Laparoscopy, Letrozole, Metformin, Polycystic ovarian syndrome

\section{INTRODUCTION}

Polycystic ovarian syndrome is the most common cause of anovulatory infertility affecting childbearing age group commonly. ${ }^{1,2}$ Its prevalence is reported from $6-18 \% .^{3,4}$ Patients with PCOS present with menstrual irregularity, hirsutism, acne, infertility etc. Laboratory investigation are suggestive of hyperandrogenaemia, increased serum LH and altered lipid profile. Ultrasonography shows polycystic ovaries as derangement in factors involved in normal follicular development leads to arrest of follicular growth so that dominant follicle does not develop and ovulation does not ensue. ${ }^{5-7}$ As women with PCOS are at increased risk of diabetes, hypertension, cardiovascular disease, hyperestrogen related cancer, thorough evaluation and treatment should be done. ${ }^{8}$

The diagnosis of PCOS was done on bases of Rotterdam criteria.

- Oligo/ anovulation

- Clinical and/or biochemical hyperandrogenism

- polycystic ovary (on USG, there are presence of more than 20 follicle with $2-9 \mathrm{~mm}$ diameter in one or both ovaries, increased ovarian volume $\left(>10 \mathrm{~cm}^{3}\right)$ in one or both ovaries). Any two of this three should present for diagnosis of PCOS. ${ }^{5-7,9-11}$ 


\section{METHODS}

Between May 2019 to April 2020, 100 cases of infertility with PCOS were studied at tertiary care hospital. Women presenting with infertility were subjected to detailed history taking, general and gynecological examination. History was obtained like age, type of infertility, menstrual history, obstetric history, sexual history, past medical and surgical history. General examination to obtain height, weight, BMI, hirsutism was done. Laboratory investigation like serum LH (on day 2 of menstruation), serum FSH (on day 2 of menstruation), prolactin, serum TSH, serum triiodothyronine (T3), serum thyroxin (T4) were done. Ultrasonographic evaluation was carried out in all patients. Semen analysis of all male partners were done.

\section{Inclusion criteria}

- $\quad$ Age between 15-35 years

- Both primary and secondary type of infertility

- Patients with all type of socio-economic status and demographic groups.

\section{Exclusion criteria}

- Patients with any cause of infertility other than PCOS

- Patients with high prolactin level

- Patients with deranged thyroid function

- Male partners having abnormal semen analysis

- Diabetes mellitus or other medical disorder.

Management option for PCOS are clomiphene citrate, letrozole, metformin and laparoscopic ovarian drilling. Clomiphene citrate was given with starting dose of 25 $\mathrm{mg} /$ day on day 2 to 6 of menstruation. Dose of clomiphene citrate could be increase up to $150 \mathrm{mg}$. Letrozole was given with starting dose of $2.5 \mathrm{mg} /$ day on day 2 to 6 of menstruation and increased up to $7.5 \mathrm{mg}$. In all cases who treated with clomiphene citrate and letrozole were followed up with ultrasonography for follicular development and ovulation from day 9 of menstruation. Ovulation was assessed by rupture of follicle and free fluid in pouch of Douglas. Metformin was given in dose of 250-500 mg/day and gradually increased by 3-4 weeks.

\section{Statistical analysis}

Statistical analysis was done using SPSS software. The $\mathrm{p}$ value of $<0.05$ was considered statistically significant.

\section{RESULTS}

During study period, 100 females with infertility were consulted and among them 60 were belong to 21-25 years of age group (Table 1). This indicates that PCOS is a disease of young age. Among 100 patients studied 70 were coming with complain of menstrual irregularities,
12 were having hirsutism and acne and 18 were having obesity (Table 2). Among 100 patients 74 were having primary infertility and 26 were having secondary infertility (Table 4). On USG examination, 82 females had enlarged ovary and 18 had normal ovary (Table 5). Normal LH:FSH ratio in early follicular phase is about 1. There were increase in LH:FSH ratio in 95 females (Table 6).

Table 1: Age distribution among cases of PCOS.

\begin{tabular}{|ll|}
\hline Age of patients (years) & Total no. of cases $(\mathbf{n}=\mathbf{1 0 0})$ \\
\hline $15-20$ & 3 \\
\hline $21-25$ & 60 \\
\hline $26-30$ & 35 \\
\hline $31-35$ & 2 \\
\hline
\end{tabular}

The maximum number of patients in the study group are seen in the age group of 21-25 years (Table 1).

Menstrual irregularities are the most common presenting symptom (Table 2).

Table 2: Frequency of complain associated with PCOS.

\begin{tabular}{|ll|}
\hline Complain & Total no. of cases $(\mathbf{n}=\mathbf{1 0 0})$ \\
\hline Infertility & 100 \\
\hline Menstrual irregularity & 70 \\
\hline Hirsutism, acne & 12 \\
\hline Obesity & 18 \\
\hline
\end{tabular}

Table 3: Menstrual patterns in PCOS.

\begin{tabular}{|lll|}
\hline \multicolumn{2}{|c|}{ Characteristics } & $\begin{array}{l}\text { Total no. of cases } \\
(\mathbf{n = 1 0 0 )}\end{array}$ \\
\hline \multirow{3}{*}{$\begin{array}{l}\text { Menstrual } \\
\text { history }\end{array}$} & Normal menses & 30 \\
\cline { 2 - 3 } & Oligomenorrhea & 45 \\
\cline { 2 - 3 } & Irregular cycle & 23 \\
\cline { 2 - 3 } & Amenorrhea & 2 \\
\hline
\end{tabular}

Patients with oligomenorrhea (less than 6 cycle/year) are commonly associated with PCOS (Table 3).

Primary infertility most commonly associate with PCOS (Table 4).

Most of the patients with PCOS are having enlarged ovary. So that ultrasonographic evaluation must be done in all patients (Table 5).

In women with PCOS, serum LH level are increased and low to normal FSH level leads to increased LH:FSH ratio (Table 6).

Among 100 patients studied, 30 patients were given clomiphene citrate, 30 were given letrozole, 30 were given metformin and 10 were subjected to ovarian drilling. Pregnancy outcome was studied among them. 
Table 4: Type of Infertility in PCOS.

\begin{tabular}{|lll|}
\hline Characteristic & Total no. of cases $(\mathbf{n}=\mathbf{1 0 0})$ \\
\hline Types of & Primary & 74 \\
\cline { 2 - 3 } infertility & Secondary & 26 \\
\hline
\end{tabular}

Table 5: Ultrasonographic co-relation with cases of PCOS.

\begin{tabular}{|ll|}
\hline On USG & Total no. of cases $(\mathbf{n}=\mathbf{1 0 0})$ \\
\hline Enlarged Ovary & 82 \\
\hline Normal Ovary & 18 \\
\hline
\end{tabular}

Table 6: Co-relation of LH:FSH ratio with cases of PCOS.

\begin{tabular}{|ll|}
\hline LH:FSH ratio & Total no. of cases $(\mathbf{n}=\mathbf{1 0 0})$ \\
\hline$<1$ & 5 \\
\hline $1-2$ & 37 \\
\hline$>2$ & 58 \\
\hline
\end{tabular}

Laparoscopic ovarian drilling has highest conception or success rates (Table 7).

Table 7: Outcome in different modalities of treatment of PCOS.

\begin{tabular}{|lll|}
\hline Modalities of treatment & $\begin{array}{l}\text { Conception } \\
\text { rate (\%) }\end{array}$ & $\begin{array}{l}\text { Failure } \\
\text { rate (\%) }\end{array}$ \\
\hline Clomiphene citrate & $15(50 \%)$ & $15(50 \%)$ \\
\hline Letrozole & $19(63 \%)$ & $11(37 \%)$ \\
\hline Metformin & $10(33.3 \%)$ & $20(66.7 \%)$ \\
\hline $\begin{array}{l}\text { Medical management } \\
\text { with laparoscopic } \\
\text { ovarian drilling }\end{array}$ & $8(80 \%)$ & $2(20 \%)$ \\
\hline
\end{tabular}

There is significant difference in ovulation or success rate for all different treatment modalities. $p$ value for ovulation is 0.0304 (Figure 1) (p value $<0.05$ at $5 \%$ level of significance.

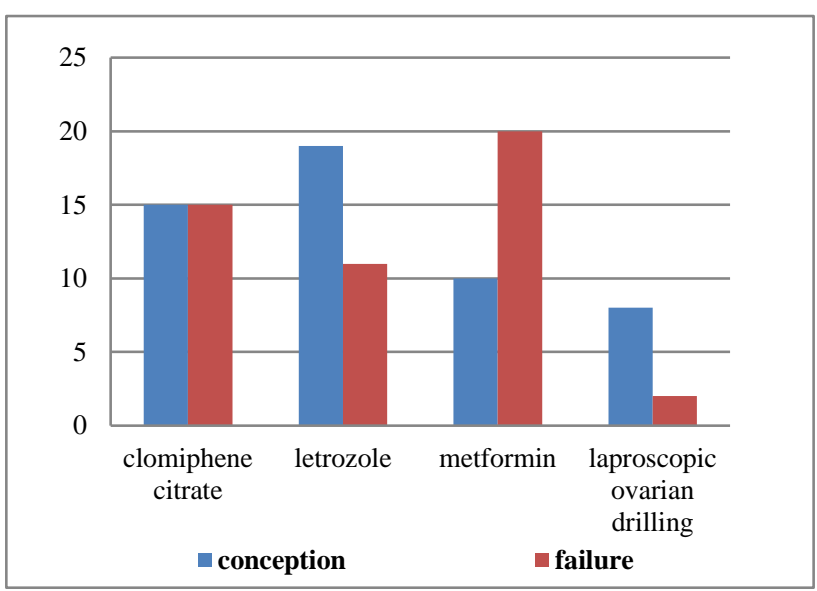

Figure 1: Association between different modalities of treatment and their outcome in PCOS.

\section{DISCUSSION}

PCOS affects women of reproductive age group with mean age of 25 years. This shows that PCOS is a disease of young age and may leads to cancer and cardiovascular risk in elder age. In this study of infertility with PCOS $74 \%$ females have primary infertility and $26 \%$ females have secondary infertility. Most women with infertility are having associated symptoms of menstrual irregularity, hirsutism, acne and obesity. Weight reduction with dietary modification and exercise may lead to increase chances of fertility. ${ }^{12}$ In this study women with menstrual irregularities are having $70 \%$ chances to be diagnose as having PCOS. In this study, on USG $82 \%$ women of PCOS having enlarged ovary and $18 \%$ women have normal ovary. So that USG findings should have to be collaborated with clinical manifestation and other laboratory data. The sensitivity of USG in detecting PCOS is therefore best diagnosing method in this study. It is also mentioned in prospective study of Atiomo WU et al. $^{13}$ Derangement in gonadotropin ratio occurs in PCOS due to increase in LH levels with low to normal FSH levels. This is due to increased amplitude and frequency of LH pulse. In this study $95 \%$ of women were having increased LH:FSH ratio. Ovulation induction with clomiphene citrate and letrozole are used as a main stay of treatment. In this study, ovulation induction with clomiphene citrate shows $50 \%$ conception rate. Ovulation induction with letrozole shows $63 \%$ conception rate. This conception rate is comparable to Guang HJ et al study. ${ }^{14}$ With regard to metformin, conception rate $10 \%$. So that in resistant cases with clomiphene citrate, metformin with clomiphene citrate lead to higher birth rate. The main indication for laparoscopic ovarian drilling is resistant case with ovulation induction drugs with anovulatory PCOS. In this study conception rate with treatment with laparoscopic drilling are $80 \%$.

\section{CONCLUSION}

There is wide range of age of distribution with mean age of 25 years.

Menstrual irregularities are the most common associated complain with infertility.

Primary infertility is more common than secondary infertility associated with PCOS.

Ultrasonography with biochemical evaluation is more accurate in diagnosing PCOS.

Recent trend of sedentary lifestyle and high fat diet leads to weight gain in adolescent girls, which eventually leads to PCOS in later life. So, lifestyle modification with weight reduction may prevent occurrence of PCOS.

PCOS has high prevalence in infertile women. Apart from reproductive outcome, PCOS leads to potential 
metabolic and cardiovascular risks if not managed properly.

\section{ACKNOWLEDGMENTS}

Authors would like to thank to all faculties colleague, post graduate residents.

Funding: No funding sources Conflict of interest: None declared

Ethical approval: The study was approved by the Institutional Ethics Committee

\section{REFERENCES}

1. Meier RK. Polycystic ovarian syndrome. Nurs Clin North Am. 2018;53:407-20.

2. Marciniak A, Lejman-Larysz K, NawrockaRutkowska J. Polycystic ovary syndrome-current state of knowledge. Pol Merkur Lekarski 2018;44:296-301.

3. Teede H, Deeks A, Moran L. Polycystic ovary syndrome: a complex condition with psychological, reproductive and metabolic manifestations that impacts on health across the lifespan. BMC Med. 2010;8:41.

4. Saad AK. Polycystic ovary syndrome: diagnosis and management of related infertility. Obstet Gynaecol Reprod Med. 2009;19:263-70.

5. Kamboj MK, Bonny AE. Polycystic ovary syndrome in adolescence: diagnostic and therapeutic strategies. Transl Pediatr. 2017;6:248-55.

6. The Rotterdam ESHRE/ASRM-Sponsored PCOS Consensus Workshop Group Revised 2003 consensus on diagnostic criteria and long term health risks related to polycystic ovary syndrome. Fertil Steril. 2004;81:19-25.

7. The Rotterdam ESHRE/ASRM-Sponsored PCOS Consensus Workshop Group Revised 2003 consensus on diagnostic criteria and long term health risks related to polycystic ovary syndrome. Hum Reprod. 2004;19:41-7.

8. Palomba S, Santagi S, La Sala GB. Compilation and challenges associated with polycystic ovarian syndrome: current perspectives. Int $\mathrm{J}$ Womens Health. 2015;7:745-63.

9. Zawadski JK, Dunaif A. Diagnostic criteria for polycystic ovary syndrome: towards 417 a rational approach. Polycyst. 1992;418:377-84.

10. Azziz R, Carmina E, Dewailly D, Diamant Kandarakis E, Escobar-Morreale HF. The Androgen Excess and PCOS Society criteria for the polycystic ovary syndrome: the complete task force report. Fertile Steril. 2009;91(2):456-88.

11. Fr DD Tarlatzis R. Revised 2003 consensus on diagnostic criteria and long-term health risks related to polycystic ovary syndrome. Fertil Steril. 2004;81(1).

12. Butterworth J, Deguara J, Borg CM. Bariatric surgery, polycystic ovary syndrome, and infertility. J Obes. 2016;2016.

13. Atiomo WU, Pearson S, Shaw S, Dubbins $P$. Ultrasound criteria in the diagnosis of PCOS. Ultrasound Med Biol. 2000;19:41-7.

14. Guang HJ, Feng L, Jun S. Letrozole for patients with polycystic ovary syndrome. Med. 2018;97:44.

Cite this article as: Deliwala KJ, Patel ZJ, Shah PT, Dholakiya D. Study of hundred cases of infertility in polycystic ovarian syndrome and its management outcome. Int J Reprod Contracept Obstet Gynecol 2020;9:3377-80. 